\title{
UKnowledge
}

University of Kentucky

UKnowledge

\section{Moderating Effects of Immunosuppressive Medications and Risk Factors for Post-Operative Joint Infection Following Total Joint Arthroplasty in Patients with Rheumatoid Arthritis or Osteoarthritis}

Elizabeth G. Salt

University of Kentucky, elizabeth.salt@uky.edu

Amanda T. Wiggins

University of Kentucky, amandathaxtonwiggins@gmail.com

Mary Kay Rayens

University of Kentucky, mkrayens@uky.edu

Brent J. Morris

Lexington Clinic

David M. Mannino

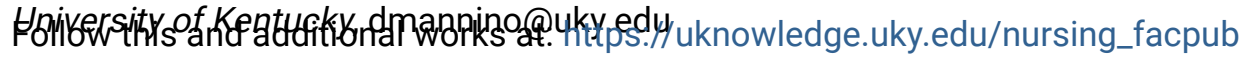

Part of the Nursing Commons, and the Pharmacy and Pharmaceutical Sciences Commons

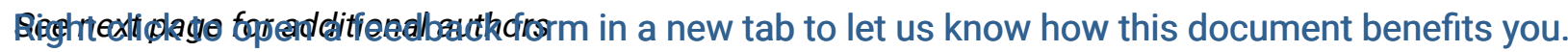

\section{Repository Citation}

Salt, Elizabeth G.; Wiggins, Amanda T.; Rayens, Mary Kay; Morris, Brent J.; Mannino, David M.; Hoellein, Andrew; Donegan, Ryan P.; and Crofford, Leslie J., "Moderating Effects of Immunosuppressive Medications and Risk Factors for Post-Operative Joint Infection Following Total Joint Arthroplasty in Patients with Rheumatoid Arthritis or Osteoarthritis" (2017). Nursing Faculty Publications. 40.

https://uknowledge.uky.edu/nursing_facpub/40

This Article is brought to you for free and open access by the College of Nursing at UKnowledge. It has been accepted for inclusion in Nursing Faculty Publications by an authorized administrator of UKnowledge. For more information, please contact UKnowledge@lsv.uky.edu. 


\section{Moderating Effects of Immunosuppressive Medications and Risk Factors for Post-Operative Joint Infection Following Total Joint Arthroplasty in Patients with Rheumatoid Arthritis or Osteoarthritis}

Digital Object Identifier (DOI)

https://doi.org/10.1016/j.semarthrit.2016.08.011

Notes/Citation Information

Published in Seminars in Arthritis and Rheumatism, v. 46, issue 4, p. 423-429.

(C) 2016 Elsevier Inc. All rights reserved.

This manuscript version is made available under the CC-BY-NC-ND 4.0 license https://creativecommons.org/licenses/by-nc-nd/4.0/.

The document available for download is the author's post-peer-review final draft of the article.

Authors

Elizabeth G. Salt, Amanda T. Wiggins, Mary Kay Rayens, Brent J. Morris, David M. Mannino, Andrew Hoellein, Ryan P. Donegan, and Leslie J. Crofford 


\title{
Moderating Effects of Immunosuppressive Medications and Risk Factors for Post-Operative Joint Infection Following Total Joint Arthroplasty in Patients with Rheumatoid Arthritis or Osteoarthritis
}

\author{
Elizabeth Salt, PhD, APRN ${ }^{1}$, Amanda T. Wiggins, $\mathrm{PhD}^{2}$, Mary Kay Rayens, $\mathrm{PhD}^{3}$, Brent J. \\ Morris, MD ${ }^{4}$, David Mannino, MD $^{5}$, Andrew Hoellein, MD $^{6}$, Ryan P. Donegan, MD ${ }^{7}$, and \\ Leslie J. Crofford, MD 8 \\ 1315 College of Nursing Building, University of Kentucky, Lexington, KY 40536-0232; United \\ States; Telephone: 859-433-5393 \\ 2315 College of Nursing Building, University of Kentucky, Lexington, KY 40536-0232; United \\ States \\ 3315 College of Nursing Building, University of Kentucky, Lexington, KY 40536-0232; United \\ States \\ ${ }^{4}$ Lexington Clinic 700 Bob-O-Link Dr. Lexington, KY 40504 \\ ${ }^{5}$ University of Kentucky Department of Public Health/Internal Medicine, 111 Washington Ave \\ Lexington, KY 40536 \\ ${ }^{6}$ Internal Medicine 800 Rose Street, Lexington, KY 40536 \\ ${ }^{7}$ Bluegrass Orthopeadics and Hand Care 3480 Yorkshire Medical Park Lexington, KY 40509 \\ 81211 Medical Center Drive Nashville, TN 37232
}

\begin{abstract}
Objective-Inconclusive findings about infection risks, importantly the use of immunosuppressive medications, in patients who have undergone large-joint total joint arthroplasty challenge efforts to provide evidenced-based perioperative total joint arthroplasty recommendations to improve surgical outcomes. Thus, the aim of this study was to describe risk factors for developing a postoperative infection in patients undergoing TJA of a large joint [total hip arthroplasty, total knee arthroplasty, or total shoulder arthroplasty] by identifying clinical and demographic factors, including the use of high risk medications (i.e., prednisone and immunosuppressive medications) and diagnoses (i.e., rheumatoid arthritis [RA], osteoarthritis [OA], gout, obesity, diabetes mellitus), that are linked to infection status, controlling for length of follow-up.
\end{abstract}

Correspondence to: Elizabeth Salt.

Publisher's Disclaimer: This is a PDF file of an unedited manuscript that has been accepted for publication. As a service to our customers we are providing this early version of the manuscript. The manuscript will undergo copyediting, typesetting, and review of the resulting proof before it is published in its final citable form. Please note that during the production process errors may be discovered which could affect the content, and all legal disclaimers that apply to the journal pertain. 
Methods-A retrospective, case-control study $(N=2,212)$ using de-identified patient health claims information from a commercially-insured, U.S. dataset representing 15 million patients annually (January 1, 2007 - December 31, 2009) was conducted. Descriptive statistics, t-test, chisquare test, Fisher's exact test, and multivariate logistic regression were used.

Results-Male gender $(O R=1.42 ; p<.001)$, diagnosis of RA $(O R=1.47 ; p=.031)$, diabetes mellitus $(O R=1.38, p=.001)$, obesity $(O R=1.66, p<.001)$ or gout $(O R=1.95 ; p=.001)$, and a prescription for prednisone $(O R=1.59 ; p<.001)$ predicted a post-operative infection following total joint arthroplasty. Persons with post-operative joint infections were significantly more likely to be prescribed allopurinol $(p=.002)$ and colchicine $(p=.006$; no significant difference was found for the use of specific disease modifying anti-rheumatic drugs and TNF-a inhibitors.

Conclusion-High-risk, post-operative joint infection groups were identified allowing for precautionary clinical measures to be taken.

\section{Keywords}

Total joint arthroplasty; infections; risk factors; immunosuppressive medications; perioperative management; case-control study

\section{Introduction}

Due to the high number of persons undergoing total large joint arthroplasty in the U.S., a clear understanding of the risk of infection and related hospital readmissions and surgical revisions is important [1-8]. Specifically, in the U.S., there were 719,000 total knee arthroplasties -, 332,000 total hip arthroplasties, and 29,127 total shoulder arthroplasties carried out in 2010 with annual costs estimated to be $\$ 18.7$ billion.[1-3] Infection is reported as a leading cause of hospital readmission following a total joint arthroplasty (post-operative joint infection rates: $0.3 \%$ - 0.7\%).[4-6] An estimated 14\% of hospital readmissions following total joint arthroplasty are a result of deep or superficial surgical site infection and $44 \%$ of joint revisions are a result of infections.[4-8]

In efforts to improve infection rates, prior research studies have identified high-risk groups which have included: male gender (odds ratio [OR]: total knee arthroplasty - 1.89; total shoulder arthroplasty - 2.59; total joint arthroplasty - 1.79); age older or younger than 56 65 years (OR: total knee arthroplasty - 1.42 - 2.59); diagnosis of diabetes mellitus (DM; OR: total knee arthroplasty - 1.28; total hip arthroplasty - 1.77); scoring at or higher than 2 on the American Society of Anesthesiologist Scale (OR: total knee arthroplasty - 1.42 - 1.65; total hip arthroplasty - 1.95 - 2.74; TSA - 1.41); history of cancer (OR: total knee arthroplasty 11.73); higher Charlson Comorbidity Score (OR: total joint arthroplasty - 2.29 [Score 22]; total knee arthroplasty - 2 [Score $>3]$ ); current smoker (OR: total knee arthroplasty or total hip arthroplasty - 1.41); and Body Mass Index $\geq 35$ (OR: total knee arthroplasty - 1.47; total hip arthroplasty -3.02; total shoulder arthroplasty - 2.48). Yet, there are inconsistencies in the variables investigated and study findings.[7-18] Similarly, many of these risk factors are largely unmodifiable in the perioperative period.

Because of the potential for modification, an understanding of risks of immunosuppressive medications on rates of infection and readmission following total joint arthroplasty is 
needed. Prior research on this topic is largely based on studies of rheumatoid arthritis (RA) patients.[8,19,20] Research suggests use of traditional disease modifying antirheumatic drugs (DMARDs), a nonbiologic class of immunosuppressive medications used to treat RA, prior to surgery does not increase infection risk.[20] In contrast, steroid use has been found to increase risks of infection and hospital readmission.[19,21] There are conflicting findings on TNF inhibitor use (biologic medications used to treat RA) and infection risk.[20-26]

Studies investigating the role of immunosuppressive medications in RA patients have not clearly described the role of treatment versus disease-related (inflammatory arthritis versus noninflammatory arthritis) effects on postoperative infection risks. [9,10,27-29] Two retrospective U.S. studies found no difference in infection rates between those diagnosed with RA versus osteoarthritis (OA) in persons who had undergone a total hip arthroplasty or total knee arthroplasty.[9,10] Yet, a number of studies have reported increased risks of infection in patients with RA ranging from two to four times that of patients with OA. $[5,15,19,27]$ Singh and colleagues $(N=34,311)$ recently reported that persons with RA are 1.29 times more likely to be readmitted to the hospital for post-surgical complications (infection leading cause), and that these rates were increasing yearly $(0.85,1.37$, and 1.63 in 2009, 2010, and 2011, respectively).[4] Interpretation of the literature is complicated by the inconsistent antibiotic protocols, definitions of infection, and sampling.[28]

Evidence-based perioperative management for total joint arthroplasty is limited by the lack of conclusive research findings about risk factors, the role of immunosuppressive medications, and the role of type of arthritis (OA versus RA) in the development of an infection following total joint arthroplasty.[9,10,27, 29] The aim of this study was to describe risk factors for developing post-operative infections in patients undergoing total joint arthroplasty of a large joint (total hip arthroplasty, total knee arthroplasty, or total shoulder arthroplasty). To achieve this aim, initially we identified clinical and demographic factors, including the use of high risk medications (i.e., prednisone and immunosuppressive medications) and diagnoses (i.e., gout, obesity, DM, RA, OA), that are linked to infection status, controlling for length of follow-up by comparing cases and control and using logistic regression modeling. During this iterative process, we further explored the potential for clinical and demographic factors that moderate the relationship between RA/OA diagnosis and infections post-operatively.

\section{Materials and Methods}

\subsection{Procedure and Sample}

De-identified patient health claims information was extracted retrospectively from a dataset representing a commercially-insured, U.S. population of 15 million patients annually from January 1, 2007 to December 31, 2009. This dataset includes 1,284,681 prescribers and 3,631 health care provider designations from all geographic regions in the U.S. Patient-level data was extracted including: administrative demographic data (e.g., gender, age), pharmacy claims data (e.g., national drug code), and physician and facility claims (e.g., procedure codes, diagnosis codes). Medical Institutional Review Board approval was obtained for the use of this dataset. 
First, all patients with the diagnosis of OA (ICD-9: 715.0 - 715.9) and RA (ICD-9: 714.0, 714.2, 714.4) who had a total joint arthroplasty (CPT codes: total knee arthroplasty - 27447; total hip arthroplasty - 27130; total shoulder arthroplasty - 23472) were extracted from the database which resulted in 55,861 unique persons. Patients who developed a post-operative joint infection following total joint arthroplasty surgery (ICD-9: 996.66 - Infection and inflammatory reaction due to internal joint prosthesis) were identified as cases (Figure 1). Of the 55,861 patients followed during this 2-year period, 1,127 developed a post-operative infection following total joint arthroplasty surgery and therefore were defined as cases in this study. Only one operative event was included for a given patient. If a patient had more than one total joint arthroplasty, only the first surgery was retained in this analysis. The only exception to this was if a patient had a subsequent total joint arthroplasty surgery that resulted in infection; in this case, only the information from the first surgery associated with an infection was retained. Controls were randomly selected to frequency match cases based on age (within 10-year increments) with a 1:1 sampling ratio; therefore only persons with complete data on matching criteria were eligible. Ten cases had missing data on year of birth and were excluded from the study; 11 cases were omitted because they did not have confirmation of OA or RA diagnosis, since the corresponding ICD-9 code was listed only once in their record; therefore the final sample consisted of 2,212 patients: 1,106 cases and 1,106 controls.

\subsection{Measures}

2.2.1. Demographic and clinical characteristics-Demographic information extracted from the database included age, gender, and race (White, Other race). We also retained information on surgery location (i.e., hip, knee, or shoulder) and time between date of surgery and end of study (i.e., length of follow-up in days). Based on prior research, ICD-9 codes were used to extract clinical information for comorbid conditions including: human immunodeficiency virus infection and acquired immune deficiency syndrome [HIV/ AIDS], immunodeficiency conditions, cancer, systemic lupus erythematosus [SLE], diabetes mellitus [DM], obesity/morbid obesity, and gout.[30-33]

We also collected information on concomitant prescription drug information. Prednisone was abstracted as dose (mg) and supply (days) for each individual; only prescriptions within one month before surgery or following, which we defined as the perioperative period, were included. Because the majority of the sample (77\%) was not prescribed prednisone, a binary variable indicating yes or no to prednisone use was created to include in the analysis. Medications were classified as immunosuppressive based on an updated Center for Disease Control list of Immunosuppressive Medications.[34]

2.2.2. Infection status-Medical outcome data were used to identify patients receiving treatment for post-operative joint infections (ICD-9: 996.66 - Infection and inflammatory reaction due to internal joint prosthesis). For each patient, a binary variable was created to indicate whether or not the patient received care for an infection attributed to the total joint arthroplasty. This variable was used to distinguish cases and controls, and was the outcome in this study. 


\subsection{Data Analysis}

Data were summarized using descriptive statistics. Initially, comparisons of study variables between cases and controls were accomplished using the two-sample t-test, Mann-Whitney $\mathrm{U}$ test, chi-square test of association or Fisher's exact test. Then, a series of logistic regression models were used. First, a main effects model was fit to identify demographic and clinical characteristics predictive of infection status. In addition to typical demographic/ clinical factors, we also included length of follow-up in each model as an adjustment for longer median follow-up among cases relative to controls. Through an iterative process, a test of moderation between diagnosis of RA or OA and post-operative infection status was conducted using a second logistic regression model which included the interactions between diagnosis (RA vs. OA) and the potential moderator variables (i.e., each demographic and clinical factor). Due to the concern about estimate stability, interaction terms involving conditions of very low prevalence (i.e., cancer, immunodeficiency, SLE, each affecting less than $5 \%$ of sample) were not included. In a subsequent analysis, all nonsignificant interactions were removed from the model. For the significant interaction effects retained, the association between RA or OA diagnosis and infection risk was evaluated at each level of the moderator variable. The Hosmer-Lemeshow goodness-of-fit test evaluated overall model fit, and variance inflation factors were used to check for multicollinearity. For these data analyses, SAS version 9.3 was used with an alpha level of .05.

\section{Results}

\subsection{Description of Sample}

The mean age of the case-control sample was 59.8 years ( $S D=10.2$ years). The majority of the sample was female (51.1\%) and White (83.1\%; Table 1). The most common total joint arthroplasty was total knee arthroplasty (61.5\%), followed by total hip arthroplasty (35.7\%) and total shoulder arthroplasty (2.8\%); the median length of follow up among all patients was 555 days. The prevalence of comorbid conditions included obesity (30.5\%), DM (29.4\%), gout (6.4\%), SLE (2.5\%), cancer (2.5\%), an immunodeficiency condition (1.0\%), and/or HIV/AIDS $(0.4 \%)$. Nearly one-quarter of patients $(22.7 \%)$ were prescribed prednisone in the two-month perioperative period; $13.5 \%$ took at least one immunosuppressive medication during the perioperative period. In the total sample, among those on prednisone, the median average daily dose was $0.16 \mathrm{mg}(0.07 \mathrm{mg}-0.47 \mathrm{mg})$.

\subsection{Identification of Clinical and Demographic Risk Factors}

When comparing cases to controls, those with an infection were more likely to be male (52.1\% vs. $45.7 \% ; p=.002$; Table 1 ). Persons who experienced an infection also had a longer median length of follow up (577 days) compared with those who did not (526 days; $p$ $<.001$ ). In addition, persons in the case group (i.e., those with an infection) were more likely to have been diagnosed with lupus (3.4\% vs. $1.6 \% ; p=.007)$, DM (34.1\% vs. $24.8 \% ; p<$. $001)$, obesity ( $35.8 \%$ vs. $25.2 \% ; p<.001)$, and gout ( $8.9 \%$ vs. $3.9 \% ; p<.001)$. Those with infections were more likely to have an RA diagnosis compared to those in the control group $(9.2 \%$ vs. $6.1 \%, p=.005)$. Consistent with the age-matching of controls with cases, there was no difference on age $(t=0.4 ; p=.7)$. In addition, cases and controls did not differ on race, surgery location, or prevalence of cancer, immunodeficiency conditions, or HIV/AIDS. 
In the bivariate analysis of medication use relative to post-operative infection status, a higher proportion of cases were prescribed prednisone $(27.7 \%$ vs. $17.7 \% ; p<.001)$ or an immunosuppressive medication $(16.6 \%$ vs. $10.4 \% ; p<.001)$ at least once during the perioperative period, compared with controls. For each immunosuppressive drug used by at least five patients in the sample, individual drugs and drug categories were compared between cases and controls (Figures 2 and 3 ). The only significant differences between cases and controls for prevalence of specific immunosuppressive drugs and drug categories included allopurinol $\left(\chi^{2}=9.2 ; p=.002\right)$ and colchicine $\left(\chi^{2}=7.5 ; p=.006\right.$. Figures 2 and 3 also display, at the top of each bar, the percent of patients using the particular medication (or medication class) that were also diagnosed with RA. Given that the sample comprised $8 \%$ RA patients, medications with RA use prevalence in excess of this demonstrates that more RA patients were taking these drugs that would have been expected if both diagnoses were equally likely to do so. Nearly all of those using adalimumab, leflunomide, or methotrexate were RA patients, while nearly all of those using allopurinol, fluorouracil, or megestrol were OA patients (Figure 2). More than two-thirds of those taking a TNFa inhibitor or DMARD were diagnosed with RA, regardless of whether they were in the infection (case) group or not (Figure 3).

The main effects multiple logistic regression model was significant overall $\left(\chi^{2}=129.8 ; p<\right.$. 001). Length of follow-up was associated with infection risk. For each additional 100 days of follow-up, a patient was $4 \%$ more likely to have an infection in a prosthetic joint ( $O R=$ $1.04 ; p=.004$; Table 2). Males, compared to females, were $42 \%$ more likely to develop an infection post-operatively $(O R=1.42 ; p<.001)$. Patients with a DM diagnosis were $38 \%$ more likely to develop an infection, relative to those without this diagnosis $(O R=1.38 ; p=$. $001)$. Other comorbid conditions associated with increased infection risk included obesity $(O R=1.66, p<.001)$ and gout $(O R=1.95 ; p=.001)$. Controlling for demographic and clinical characteristics and length of follow-up, RA patients were $47 \%$ more likely to develop a post-operative infection, compared to patients with $\mathrm{OA}(O R=1.47 ; p=.031)$. Patients prescribed prednisone within one month before or following total joint arthroplasty surgery were 59\% more likely to develop an infection, compared to those not prescribed prednisone $(O R=1.59 ; p<.001)$. Race, total joint arthroplasty location, cancer, SLE, presence of an immunodeficiency condition, HIV/AIDS, and use of an immunosuppressive medication during the perioperative period were not predictive of post-operative infection in the main effects model. The Hosmer-Lemeshow goodness-of-fit test was not significant ( $\chi^{2}$ $=5.2 ; p=.74)$, suggesting the model fit the data well. All variance inflation factors were less than 1.4, indicating that multicollinearity was not distorting the parameter estimates.

In an effort to investigate treatment versus disease-related effects, the relationship between RA/OA diagnosis and infection identified in our primary analysis was explored using a second logistic regression model. This moderation model, which contained demographic and clinical main effects, days of follow-up, the indicator for RA/OA, and the interaction between immunosuppressive medication use and RA/OA diagnosis was significant ( $\chi^{2}=$ 8.3; $p=.004)$. Among those taking immunosuppressive medication(s) $(n=299)$, there was no difference in the odds of infection between RA $(n=71)$ and OA patients $(n=229 ; O R=$ $0.73, p=.30)$; however, among those not taking this type of medication $(n=1,913)$, RA 
patients $(n=99)$ were $130 \%$ more likely to develop an infection compared with OA patients $(n=1,814 ; O R=2.30,95 \%$ Confidence Interval: $1.37-3.30 ; p=.001)$.

\section{Discussion}

The lack of conclusive research findings about risk factors, importantly the role of immunosuppressive medications, in the development of an infection following total joint arthroplasty, has limited evidenced-based perioperative management. Similarly there is a lack of clarity on the role of disease- versus treatment-related effects on infection risk following total joint arthroplasty. In efforts to address these clinical problems, we identified risk factors for developing infections following a total joint arthroplasty of a large joint. Using an iterative process we also described the moderating relationship between the use immunosuppressive medications and the diagnosis of RA/OA in the development of a postoperative infection.

There is evidence that supports and conflicts with our finding that there is an increased risk of infection following total joint arthroplasty in patients with RA versus those with OA. Large U.S. and European studies have reported an increased risk of hospital readmissions and infections in patients with RA versus those with OA. [4,27,30] In contrast, Namba and colleagues did not find an increased risk of infection between persons with RA and OA following total hip arthroplasty or total knee arthroplasty in a retrospective analysis of data from 2001-2009.[9,10] Considering that the majority and the most recent and large studies found an increased risk of postoperative infection in patients with RA, we feel our findings are strongly supported; thus, this risk factor should be considered during clinical management.

Although the increased infection risk of RA versus OA has been further established, the question of disease- versus treatment-related effects remained.[29] Because of the study design using a large administrative dataset, we could not directly assess RA disease activity. However, importantly in our study, immunosuppressive medication use did not predict infection in our main effects model and the use of immunosuppressive medications only moderated the relationship between RA/OA diagnosis and infection in the postoperative period: while the main effects model demonstrated that RA patients were at an increased risk for infection compared with OA patients, the test of moderation indicated this phenomenon was only present among those not taking immunosuppressive medications perioperatively. These findings support prior studies suggesting there is not an increased infection risk when using immunosuppressive medications (DMARDs) prior to surgery.[19, 20] Our study conflicts with prior research reporting that patients taking biologic DMARDs within 2 to 4 weeks of surgery were 5.7 times more likely to develop an infection.[20] Of interest, persons in the this same study who had increased RA disease duration were also more likely to develop an infection.[20] We found there was not a significant different between cases and control on the use of TNF- $a$ inhibitors as a class, and this was bolstered with the casecontrol comparison of percentage using adalimumab specifically. We confirmed prior evidence to suggest that steroid use increases the risk of infection and hospital readmission. $[8,19]$ 
Our findings suggesting that, controlling for obesity and DM, gout and medications used to treat gout increase infection risk following total joint arthroplasty. These findings are supported by one study conducted by Inacio and colleagues ( $O R$ - 1.3).[27] Interestingly, a recent publication reported 7 cases of crystal induced arthritis followed total joint arthroplasty suggesting our understanding of the relationship between gout, total joint arthroplasty and infection is evolving and further exploration is needed [35]. Similarly, because the increased risk of infection has been described in two diseases with inflammatory etiologies (RA and gout), the role of inflammation in the diagnosis of postoperative infection also requires further exploration.

Prior research supports study findings that male gender, DM, and obesity predict postoperative infection following total joint arthroplasty.[9,10] Interestingly, weight loss has also been identified as a risk factor for developing a post-operative infection (OR: 2.3) complicating clinical recommendations to obese persons.[27]

The effect of cancer diagnosis on infection risk following total joint arthroplasty is conflicting in prior research. [8,31] Findings from this study suggest that persons with a history of cancer are not at increased infection risk. Although we did report the use of immunosuppressive medication use, which provides insight into cancer as an infection risk factor, further prospective research on the effects of cancer stage and specifics of cancer treatment should be conducted. Neither our findings nor prior research suggest that those diagnosed with HIV/AIDS are at increased risk of infection following total joint arthroplasty.[31] Despite our study findings, there are relatively few studies describing the risk of HIV/AIDS and cancer and postoperative infection, which limits evidenced-based practice.

A study strength is the large number of patients included relative to prior research in this area. Because this was a retrospective review of a commercial insurance database, the data available was limited by those medications and treatments that were charged by health care providers and paid for using insurance coverage. Although this was a large dataset, it represents those commercially insured and study findings may not be generalizable to other populations, including those without private insurance. The racial/ethnic composition of the sample is notrepresentative of the U.S. population, though the higher prevalence of White patients in this sample relative to the general population is consistent with previous studies of racial variations in total joint arthroplasty [36]. There is also the potential for inaccuracies in ICD-9 and CPT codes available for extraction from the dataset, though limited the analysis to those with confirmed RA/OA by requiring at least two ICD-9 codes for the respective disease in each patient retained in the analysis to prevent a diagnosis error. The modest number of persons with HIV/AIDS, cancer, SLE, and immunodeficiency conditions limit the strength of this analysis as least as it pertains to definitive understanding of the link between these conditions and infection risk. The test of moderation between RA/OA status and infection should be confirmed in a sample that includes more RA patients, and more patients who are taking immunosuppressive medications. In particular, given the relatively small percentage of patients with RA compared with OA in addition to the low prevalence of use for individual immunomodulating and immunosuppressive medications, it was not possible to investigate the relationship between infection risk and diagnosis of OA/RA for 
each of these medications. This last limitation is mitigated by the observation that the risk of infection among RA patients relative to those with OA was elevated only among those not taking immunosuppressive medications, but there was no risk differential among those who were.

\section{Conclusion}

In conclusion, this study uses a robust sample to validate previously-identified risk factors (i.e., male gender, obesity) and further clarify risk factors with conflicting or very little prior research (i.e., gout, prednisone, immunosuppressive medication use). These findings contribute to our understanding of treatment- versus disease-related infection risks following total joint arthroplasty.

\section{Acknowledgments}

This work was supported in part by the National Center for Research Resources and the National Center for Advancing Translational Sciences, National Institutes of Health [UL1TR000117]. The content is solely the responsibility of the authors and does not necessarily represent the official views of the NIH. Access to the large commercially insured dataset was made available with funding from CTSA UL1TR000117.

\section{References}

1. [accessed 4.8.2015] Center for Disease Control, Inpatient surgery. http://www.cdc.gov/nchs/fastats/ inpatient-surgery.htm

2. Trofa D, Rajaee SS, Smith EL. Nationwide trends in total shoulder arthroplasty and hemiarthroplasty for osteoarthritis. Am J of Orthop. 2014; 43:166-172. [PubMed: 24730001]

3. U.S. Department of Health and Human Services. [accessed 4.8.2015] Health, United States, 2014. http://www.cdc.gov/nchs/fastats/inpatient-surgery.htm

4. Singh JA, Inacio MCS, Namba RS, Paxton EW. Rheumatoid arthritis is associated with higher 90day hospital readmission rates compared to osteoarthritis after hip or knee arthroplasty: A cohort study. Arthritis Care Res. 2015; 67:718-724.

5. Pulido L, Ghanem E, Joshi A, Purtill JJ, Parvizi J. Periprosthetic joint infection: The incidence, timing, and predisposing factors. Clin Orthop Relat Res. 2008; 466:1710-1715. [PubMed: 18421542]

6. Rasouli M, Maltenfort MG, Purtill JJ, Hoazck WJ, Parvizi J. Has the rate of in-hospital infections after total joint arthroplasty decreased? Clin Orthop Relat Res. 2013; 471:3102-3111. [PubMed: 23575808]

7. Mortazavi SMJ, Molligan J, Austin MS, Purtill JJ, Hozack WJ, Parvizi J. Failure following revision total knee arthroplasty: Infection is the major cause. International Orthopaedics. 2011; 35:11571164. [PubMed: 20959981]

8. Pugely AJ, Callaghan JJ, Martin CT, Cram P, Gao Y. Incidence of and risk factors for 30-day readmission following elective primary total joint arthroplasty: Analysis from the ACS-NSQIP. J Arthroplast. 2013; 28:1499-1504.

9. Namba RS, Inacio MCS, Paxton EW. Risk factors associated with deep surgical site infection after primary total knee arthroplasty. J Bone Joint Surg Am. 2013; 95:775-82. [PubMed: 23636183]

10. Namba RS, Inacio MCS, Paxton EW. Risk factors associated with surgical site infection in 30,941 primary total hip replacements. J Bone Joint Surg Am. 2012; 94-B:1330-8.

11. Richards J, Inacio MCS, Beckett M, Navarro RA, Singh A, Dillon MT, et al. Patient and procedure-specific risk factors for deep infection after primary shoulder arthroplasty. Clin Orthop Relat Res. 2014; 472:2809-2815. [PubMed: 24906812]

12. Dowsey MM, Choong PFM. Obese diabetic patients are at substantial risk for deep infection after primary TKA. Clin Orthop Relat Res. 2009; 467:1577-1581. [PubMed: 18841430] 
13. Mraovic B, Suh D, Jacovides C, Parvizi J. Perioperative hyperglycemia and postoperative infection after lower limb arthroplasty. J Diabete Sci Technol. 2011; 5:412-418.

14. ämsen J, Nevalainen P, Eskelinen A, Huotari K, Kalliovalkama J, Moilanen T. Obesity, diabetes and perioperative joint infection: A single-center analysis of 7181 primary hip and knee replacement for osteoarthritis. J Bone Joint Surg Am. 2012; 94:e101-109. [PubMed: 22810408]

15. Peel TN, Dowsey MM, Daffy JR, Stanley PA, Choong PFM, Buising KL. Risk factors for prosthetic hip and knee infections according to arthroplasty site. J Hosp Infection. 2011; 79:129_ 133.

16. Singh JA, Sperling JW, Schleck C, Harmsen WS, Cofield RH. Periprosthetic infections after total shoulder arthroplasty: A 33-year perspective. J Shoulder Elbow Surg. 2013; 21:1534-1541.

17. Rasouli MR, Restrepo C, Maltenfort MG, Purtill JJ, Parvizi J. Risk factors for surgical site infection following total joint arthroplasty. J Bone and Joint Surg. 2014; 96(15):e158. [PubMed: 25232088]

18. Singh JA, Houston TK, Ponce BA, Maddox G, Bishop M, Richman J, et al. Smoking is a risk factor for short-term outcomes following primary total hip and knee replacement in veterans. Arthritis Care Res. 2011; 63:1-19.

19. Bongartz T, Halligan CS, Osmon DR, Reinalda MS, Bamlet WR, Crowson CS, et al. Incidence and risk factors of prosthetic joint infection after total hip or knee replacement in patients with rheumatoid arthritis. Arthritis Rheum 2008. 2008; 59:1713-1720.

20. Momohara S, Kawakami K, Iwamoto T, Yano K, Sakuma Y, Hiroshima R, et al. Prosthetic joint infection after total hip or knee arthroplasty in rheumatoid arthritis patients treated with nonbiologic and biologic disease-modifying antirheumatic drugs. Mod Rheumatol. 2011; 21:469_ 475. [PubMed: 21318306]

21. Gilson M, Gossec L, Mariette X, Gherissi D, Guyot D, Guyot MH, et al. Risk factors for total joint arthroplasty infection in patients receiving tumor necrosis factor-a blockers: A case-control study. Arthritis Res Therapy. 2010; 12:R145.

22. Ruyssen-Witrand A, Gossec L, Salliot C, Luc M, Duclos M, Guignard S, et al. Complication rates of 127 surgical procedures performed in rheumatic patients receiving tumor necrosis factor alpha blockers. Clin Exp Rheumol. 2007; 25:430-436.

23. Den Broeder AA, Creemers MC, Fransen J, De Jong E, de Rooij DJ, Wymenga A, et al. Risk factors for surgical site infections and other complications in elective surgery in patients with rheumatoid arthritis with special attention for anti-tumor necrosis factor: A large retrospective study. J Rheumatol. 2007; 34:689-695. [PubMed: 17117492]

24. Wendling D, Balbanc JC, Brousse A, Lohse A, Lehuede G, Garbuio P, et al. Surgery in patients receiving anti-tumor necrosis factor a treatment in rheumatoid arthritis: An observational study on 50 surgical procedures. Ann Rheum Dis. 2005; 64:1378-1379. [PubMed: 16100348]

25. Talwalkar SC, Grennan DM, Gray J, Johnson P, Hayton MJ. Tumor necrosis factor a antagonists and early postoperative complications in patients with inflammatory joint disease undergoing elective orthopaedic surgery. Ann Rheum Dis. 2005; 64:650-651. [PubMed: 15769927]

26. Kawakami K, Ikari K, Kawamura K, Tsukahara S, Iwamoto T, Yano K, et al. Complications and features after joint surgery in rheumatoid arthritis patients treated with tumour necrosis factor-a blocker: Perioperative interruption of tumour necrosis factor-a blockers decreases complications? Rheumatol. 2010; 49:341-349.

27. Inacio, MCS., Pratt, NL., Roughead, EE., Graves, SE. Predicting infections after total joint arthroplasty using a prescription based comorbidity measure. J Arthroplasty. 2015. http:// dx.doi.org/10.1016/j.arth.2015.05.004

28. Ravi B, Escott B, Shah PS, Jenkinson R, Chahal J, Bogoch E, et al. A systematic review and metaanalysis comparing complications following total joint arthroplasty for rheumatoid arthritis versus for osteoarthritis. Arthritis Rheum. 2012; 64:3839-3849. [PubMed: 23192790]

29. Singh JA, Furst PE, Bharat A, Curtis JR, Kavanaugh AF, Kremer JM, et al. Update of the 2008 ACR recommendations for the use of disease-modifying antirheumatic drugs and biologic agents in the treatment of rheumatoid arthritis. Arthritis Care Res. 2012; 64:625-639.

30. Schrama JC, Espehaug B, Hallan G, Engesaeter LB, Furnes O, Havelin LI, et al. Risk of revision for infection in primary total hip and knee arthroplasty in patients with rheumatoid arthritis 
compared with osteoarthritis: A prospective, population-based study of 108,786 hip and knee joint arthroplasties from the Norweigian arthroplasty register. Arthritis Care Res. 2015; 62:473-479.

31. Paxton EW, Inacio MCS, Singh JA, Love R, Bini SA, Namba RS. Are there modifiable risk factors for hospital readmission after total hip arthroplasty in a US healthcare system? Clin Orthop Relat Res. 2015; 473:3446-3455. [PubMed: 25845947]

32. Soo Hoo NF, Lieberman JR, Ko CY, Zingmond DS. Factors predicting complication rates following total knee replacement. J Bone Joint Surg. 2006; 88A:480-485.

33. Belmont PJ, Goodman GP, Rodriquez M, Bader JO, Waterman BR, Schoenfeld AJ. Predictors of hospital readmission following revision total knee arthroplasty. Knee Surg Sports Traumatol Arthrosc. 2015; Epub. doi: 10.1007/s00167-015-3782-6

34. Centers for Disease Control. [accessed 4.8.2015] List of Medications Contraindicating Receipt of Smallpox Vaccine. https://www.google.com/?gws_rd=ssl\#q=List+of+Medications+ + Contraindicating+Receipt+of+Smallpox+Vaccine+and+pdf

35. Yahia SA, Zeller V, Desplaces N, Chazerain P, Lhotellier L, Marmor S, et al. Crystal-induced arthritis after arthroplasty: 7 cases. Joint, Bone, \& Spine. 2016; 22:S1297-319.

36. Ibrahim SA. Racial variations in the utilization of knee and hip joint replacement: an introduction and review of the most recent literature. Curr Orthop Pract. 2010; 21:126-131. [PubMed: 21132110]

\section{Abbreviations \\ RA rheumatoid arthritis \\ OA osteoarthritis \\ U.S United States \\ OR odds ratio \\ DM diabetes mellitus}

DMARDs disease modifying anti-rheumatic drugs

TNFa tumor necrosis factor alpha

CPT current procedural terminology

ICD-9 International Statistical Classification of Disease

HIV/AIDs human immunodeficiency virus infection and acquired immune deficiency syndrome

SLE systemic lupus erythematosus 


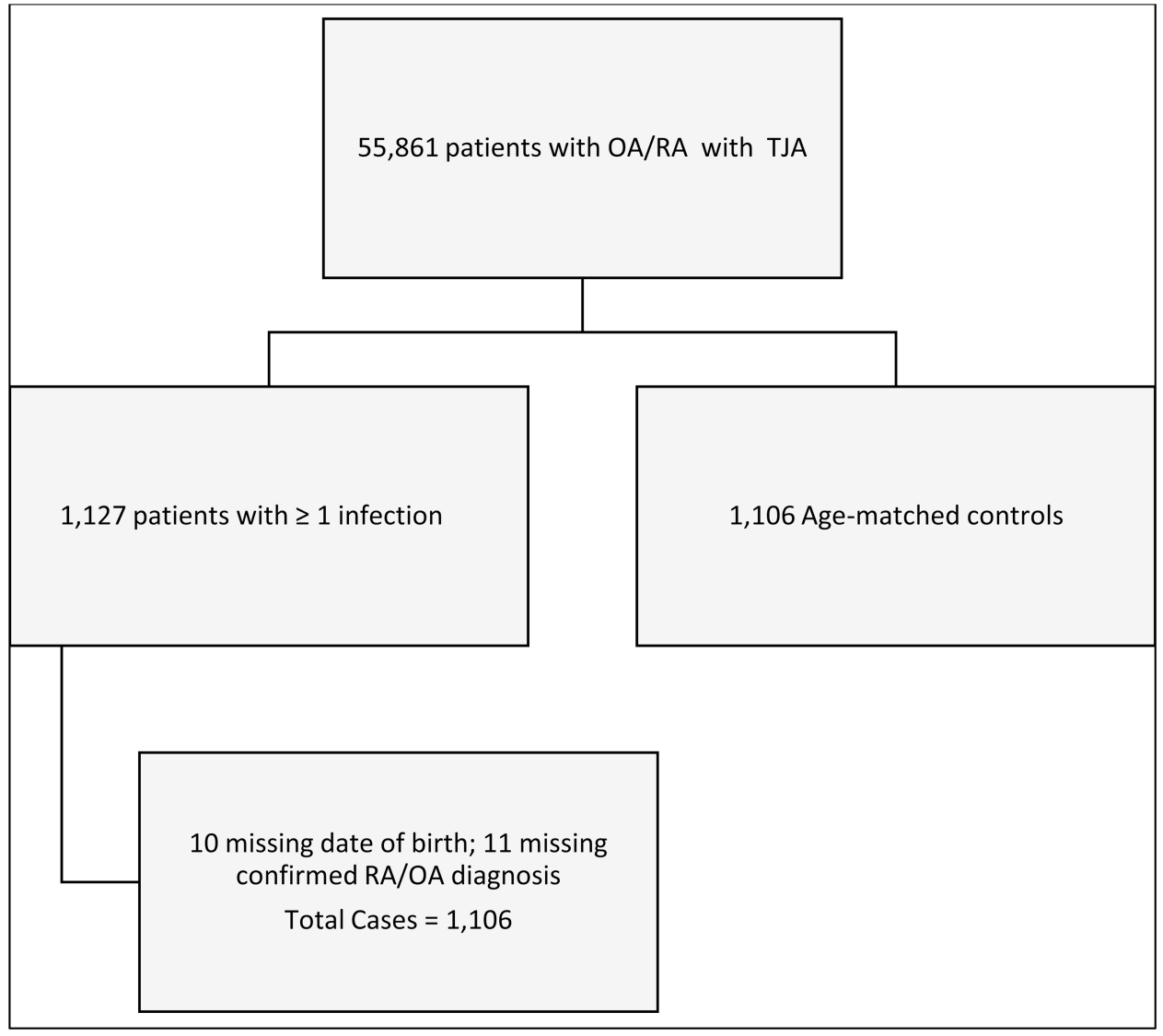

Figure 1.

Derivation of Sample. 


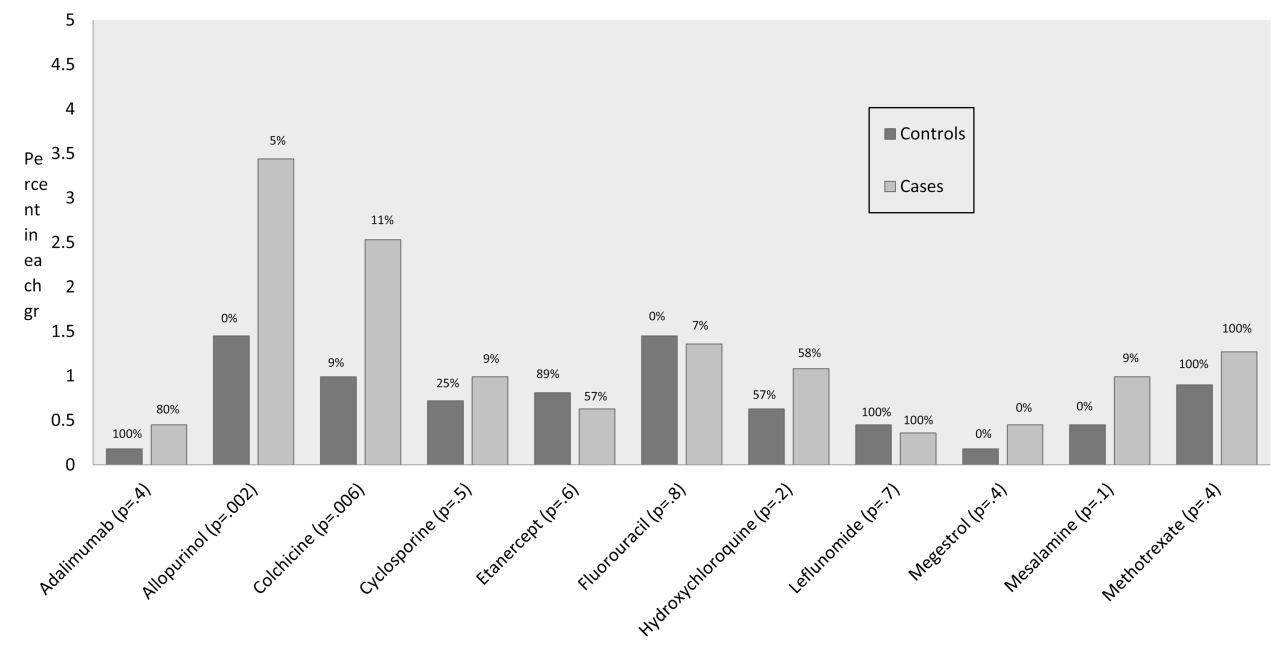

Figure 2.

Comparisons of medication usage rates between cases and controls.

Note: Above each bar is listed the percent of patients taking that drug who have RA, whether in the case or control group; this should be contrasted to $8 \%$, the percent of patients with RA in the full sample of cases and controls. For example, all patients taking Adalimumab who did not get infections had RA, and $80 \%$ of those in the case group who were taking this drug had RA. 


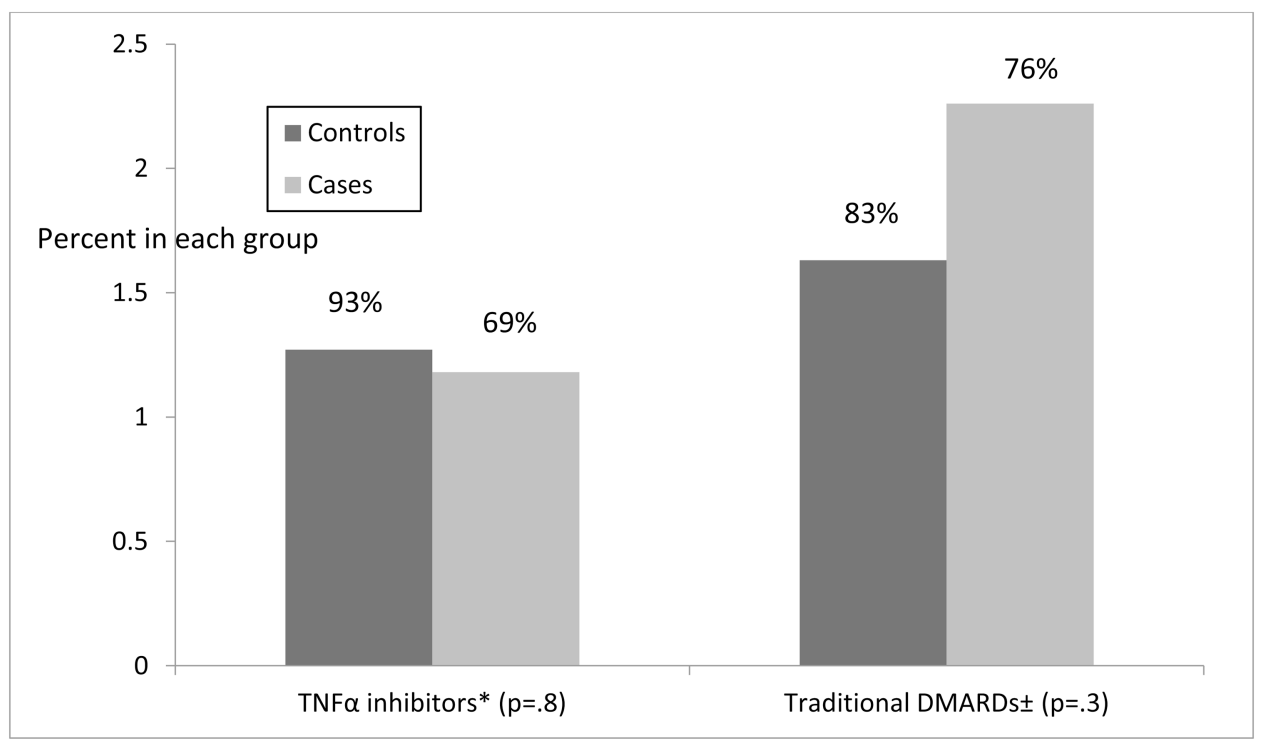

Figure 3.

Comparison of use of TNFa inhibitors and traditional DMARDs between cases and controls.

*TNFa inhibitors including Adalimumab, Certolizumab, Etanercept, Infliximab, and Golimumab

\pm Traditional DMARDS including Azathioprine, Hydroxychloroquine, Leflunomide, and Methotrexate

Note: Above each bar is listed the percent of patients taking that class of drug who have RA, whether in the case or control group; this should be contrasted to $8 \%$, the percent of patients with RA in the full sample of cases and controls. For example, $93 \%$ of patients taking a TNFa inhibitor who did not get infections had RA, and $69 \%$ of those in the case group who were taking this class of drug had RA. 
Table 1

Descriptive summary of study variables and comparisons by infection status

\begin{tabular}{|c|c|c|c|c|}
\hline & Total sample $(N=\mathbf{2 , 2 1 2})$ & Case $(n=1,106)$ & Control $(n=1,106)$ & $p$ \\
\hline Gender & & & & .002 \\
\hline Male & $1,081(48.9 \%)$ & $576(52.1 \%)$ & $505(45.7 \%)$ & \\
\hline Female & $1,131(51.1 \%)$ & $530(47.9 \%)$ & $601(54.3 \%)$ & \\
\hline Race & & & & .50 \\
\hline White & $1,838(83.1 \%)$ & $913(82.5 \%)$ & $925(83.6 \%)$ & \\
\hline Other & $374(16.9 \%)$ & $193(17.5 \%)$ & $181(16.4 \%)$ & \\
\hline Surgery location & & & & .58 \\
\hline Knee & $1,361(61.5 \%)$ & $692(62.6 \%)$ & $669(60.5 \%)$ & \\
\hline Hip & $789(35.7 \%)$ & $385(34.8 \%)$ & $404(36.5 \%)$ & \\
\hline Shoulder & $62(2.8 \%)$ & $29(2.6 \%)$ & $33(3.0 \%)$ & \\
\hline Follow-up (days) & $555(301-814.5)$ & $577(335-832)$ & $525.5(260-786)$ & $<.001$ \\
\hline Cancer & & & & .13 \\
\hline Yes & $55(2.5 \%)$ & $33(3.0 \%)$ & $22(2.0 \%)$ & \\
\hline No & $2,157(97.5 \%)$ & $1,073(97.0 \%)$ & $1,084(98.0 \%)$ & \\
\hline Lupus (SLE) & & & & .007 \\
\hline Yes & $56(2.5 \%)$ & $38(3.4 \%)$ & $18(1.6 \%)$ & \\
\hline No & $2,156(97.5 \%)$ & $1,068(96.6 \%)$ & $1,088(98.4 \%)$ & \\
\hline Immunodeficiency condition & & & & .087 \\
\hline Yes & $22(1.0 \%)$ & $15(1.4 \%)$ & $7(0.6 \%)$ & \\
\hline No & $2,190(99.0 \%)$ & $1,091(98.6 \%)$ & $1,099(99.4 \%)$ & \\
\hline HIV/AIDS & & & & .74 \\
\hline Yes & $9(0.4 \%)$ & $5(0.5 \%)$ & $4(0.4 \%)$ & \\
\hline No & $2,203(99.6 \%)$ & $1,101(99.5 \%)$ & $1,102(99.6 \%)$ & \\
\hline Diabetes & & & & $<.001$ \\
\hline Yes & $651(29.4 \%)$ & $377(34.1 \%)$ & $274(24.8 \%)$ & \\
\hline No & $1,561(70.6 \%)$ & $729(65.9 \%)$ & $832(75.2 \%)$ & \\
\hline Obesity & & & & $<.001$ \\
\hline Yes & $675(30.5 \%)$ & $396(35.8 \%)$ & $279(25.2 \%)$ & \\
\hline No & $1,537(69.5 \%)$ & $710(64.2 \%)$ & $827(74.8 \%)$ & \\
\hline Gout & & & & $<.001$ \\
\hline Yes & $142(6.4 \%)$ & $99(8.9 \%)$ & $43(3.9 \%)$ & \\
\hline No & $2,070(93.6 \%)$ & $1,007(91.1 \%)$ & $1,063(96.1 \%)$ & \\
\hline
\end{tabular}




\begin{tabular}{|c|c|c|c|c|c|}
\hline$D$ & $\begin{array}{l}\text { Yes } \\
\text { No }\end{array}$ & $\begin{array}{l}\text { Total sample }(N=\mathbf{2 , 2 1 2}) \\
502(22.7 \%) \\
1,710(77.3 \%)\end{array}$ & $\begin{array}{l}\text { Case }(\boldsymbol{n}=\mathbf{1 , 1 0 6}) \\
306(27.7 \%) \\
800(72.3 \%)\end{array}$ & $\begin{array}{l}\text { Control }(\boldsymbol{n}=\mathbf{1 , 1 0 6}) \\
196(17.7 \%) \\
910(82.3 \%)\end{array}$ & $p$ \\
\hline$\frac{\text { 을 }}{\stackrel{3}{2}}$ & $\begin{array}{l}\text { Perioperative immunosuppressive medication use } \\
\text { Yes } \\
\text { No }\end{array}$ & $\begin{array}{l}299(13.5 \%) \\
1,913(86.5 \%)\end{array}$ & $\begin{array}{l}184(16.6 \%) \\
922(83.4 \%)\end{array}$ & $\begin{array}{l}115(10.4 \%) \\
991(89.6 \%)\end{array}$ & $<.001$ \\
\hline 음. & $\begin{array}{l}\text { Diagnosis } \\
\text { Rheumatoid arthritis } \\
\text { Osteoarthritis }\end{array}$ & $\begin{array}{l}169(7.6 \%) \\
2,043(92.4 \%)\end{array}$ & $\begin{array}{l}102(9.2 \%) \\
1,004(90.8 \%)\end{array}$ & $\begin{array}{l}67(6.1 \%) \\
1,039(93.9 \%)\end{array}$ & .005 \\
\hline
\end{tabular}

Note: all statistics are reported as $n(\%)$, except days of follow-up; this is reported as median (interquartile range) 
Table 2

Multiple logistic regression modeling the likelihood of developing a post-operative infection following total joint replacement surgery $(N=\mathbf{2 , 2 1 2})$

\begin{tabular}{|c|c|c|c|}
\hline & Estimated Odds Ratio (OR) & 95\% Confidence Interval for OR & $\mathbf{p}$ \\
\hline \multicolumn{4}{|l|}{ Gender } \\
\hline Male vs. female & 1.42 & $1.19-1.70$ & $<.001$ \\
\hline \multicolumn{4}{|l|}{ Race } \\
\hline White vs. other & 0.93 & $0.74-1.17$ & .53 \\
\hline \multicolumn{4}{|c|}{ Replacement surgery location } \\
\hline Hip vs. knee & 1.01 & $0.84-1.21$ & .93 \\
\hline Shoulder vs. knee & 0.78 & $0.46-1.33$ & .36 \\
\hline Follow-up (days) ${ }^{a}$ & 1.04 & $1.01-1.07$ & .004 \\
\hline \multicolumn{4}{|l|}{ Cancer } \\
\hline Yes vs. no & 1.34 & $0.76-2.36$ & .31 \\
\hline \multicolumn{4}{|l|}{ Lupus (SLE) } \\
\hline Yes vs. no & 1.65 & $0.90-3.04$ & .11 \\
\hline \multicolumn{4}{|c|}{ Immunodeficiency condition } \\
\hline Yes vs. no & 1.78 & $0.69-4.57$ & .23 \\
\hline \multicolumn{4}{|l|}{ HIV/AIDS } \\
\hline Yes vs. no & 1.24 & $0.32-4.82$ & .76 \\
\hline \multicolumn{4}{|l|}{ Diabetes } \\
\hline Yes vs. no & 1.38 & $1.14-1.68$ & .001 \\
\hline \multicolumn{4}{|l|}{ Obesity } \\
\hline Yes vs. no & 1.66 & $1.37-2.02$ & $<.001$ \\
\hline \multicolumn{4}{|l|}{ Gout } \\
\hline Yes vs. no & 1.95 & $1.30-1.97$ & .001 \\
\hline \multicolumn{4}{|c|}{ Perioperative prednisone use } \\
\hline Yes vs. no & 1.59 & $1.28-1.97$ & $<.001$ \\
\hline \multicolumn{4}{|c|}{ Perioperative immunosuppressive medication use } \\
\hline Yes vs. no & 1.12 & $0.84-1.50$ & .44 \\
\hline \multicolumn{4}{|l|}{ Diagnosis } \\
\hline RA vs. OA & 1.47 & $1.04-2.08$ & .031 \\
\hline
\end{tabular}

Estimates correspond to a 100 day increase days of follow-up 